\title{
Considerações sobre a toponímia acreana: as marcas culturais deixadas pelos desbravadores nordestinos em nomes de seringais e colocações
}

\author{
Alexandre Melo de SOUSA ${ }^{1}$
}

\begin{abstract}
RESUMO: Neste artigo objetivamos discutir alguns aspectos referentes à toponímia dos seringais e colocações acreanas, num enfoque etnolinguístico. Prioriza-se investigar as marcas da cultura nordestina que possivelmente estejam refletidas nos topônimos selecionados. Essa escolha não é fortuita, uma vez que a história da formação acreana revela, como um de seus principais personagens, o grupo humano (a maior parte proveniente do Ceará) nordestino, que chegou ao território para trabalhar na extração do látex, favorecendo a formação dos seringais, do Estado e da própria cultura do lugar.
\end{abstract}

PALAVRAS-CHAVE: Toponímia; Léxico; Etnolinguística; Acre; Seringais; Colocações.

\section{Introdução}

A Toponímia - um dos ramos da Onomástica que trata do estudo dos nomes próprios de acidentes geográficos físicos e humanos - mostra que, através do levantamento, da classificação e da análise dos topônimos, é possível recuperar características sócio-histórico-culturais e/ou físico-geográficos que, possivelmente, motivaram o denominador no ato do batismo de um determinado espaço geográfico. Além disso, possibilita identificar estratos lingüísticos de outros grupos étnicos.

Assim, o topônimo assume valores que transcendem a função identificadora, simplesmente. Sabe-se, também, que a análise da cultura e do conjunto de valores de uma sociedade exige, precipuamente, um estudo centrado na língua - já que por meio dela que são revelados os pensamentos e os costumes dos diferentes grupos humanos.

A língua "traduz toda uma cultura, traduz todo um universo peculiar com suas implicações psicológicas e filosóficas que é preciso alcançar para enriquecimento da experiência” (BORBA, 1984, p. 07).

Diante dessas considerações, neste artigo objetivamos discutir alguns aspectos referentes à toponímia dos seringais e colocações acreanas, num enfoque

\footnotetext{
${ }^{1}$ Doutor em Linguística. Professor de Língua Portuguesa e Linguística da Universidade Federal do Acre (UFAC), onde coordena o Projeto Atlas Toponímico da Amazônia Ocidental Brasileira (ATAOB) e integra o grupo de pesquisa do Atlas Linguístico do Acre.
}

Caderno Seminal Digital Ano 16, nº 13, V. 13 (Jan.- Jun/2010) - ISSN 1806 -9142 
etnolinguístico. Prioriza-se investigar as marcas da cultura nordestina que possivelmente estejam refletidas nos topônimos selecionados. Essa escolha não é fortuita, uma vez que a história da formação acreana revela, como um de seus principais personagens, o grupo humano (a maior parte proveniente do Ceará) nordestino, que chegou ao território para trabalhar na extração do látex, favorecendo a formação dos seringais, do Estado e da própria cultura do lugar.

\section{O Acre: aspectos históricos e culturais}

O Estado do Acre, a conhecida Amazônia Ocidental Brasileira, está situado a sudoeste da Região Norte do Brasil e se limita com: Amazonas (N); Rondônia (L); Bolívia (SE); e Peru (S e O). O Estado, cuja capital é Rio Branco, tem, como cidades mais populosas, além da capital: Cruzeiro do Sul, Tarauacá, Sena Madureira e Brasiléia. Revelar a história acreana, especialmente no tocante à formação espacial e humana, é contar a história do "descobrimento" da hevea brasilienses - a seringueira: elemento que melhor representa a gênese do referido local, pois, foi a partir do produto extraído dessa árvore - o látex - que contingentes, cada vez maiores, de imigrantes foram ocupando a região, com a finalidade de trabalhar como extratores do "ouro branco", cobiçando grandes lucros e uma vida digna.

Com a chegada dos primeiros exploradores, a região foi, aos poucos sendo demarcada, dando origem aos seringais e às colocações que se formavam às margens das principais bacias hidrográficas acreanas - o Rio Juruá e o Rio Purus. Para essas populações, os rios eram de extrema importância sócio-econômica, pois eram utilizados para a locomoção, para a comunicação, para a alimentação. Enfim, para o habitante amazônico, de um modo geral, o rio significava (e significa) a própria existência humana (Cf. Tocantins, 1984, p. 32).

A migração para terras acreanas adquiriu maior impulso entre 1877 e 1879, quando houve a maior crise sócio-econômica na Região Nordeste (sobretudo no Ceará), decorrente da forte seca que assolou a região. Essa crise, somada ao incentivo e financiamento pelo Estado do Amazonas, favoreceu a migração desses povos para a região.

Lima (s/d, p. 24) registra que

[...] a primeira expedição a chegar em terras acreanas, foi a do cearense de Uruburetama, João Gabriel, com sua gente, no navio 
vapor Anajás, aportando nas barrancas do Acre (Aquiri), fundando os primeiros seringais e formando os primeiros núcleos populacionais.

Os imigrantes nordestinos, a partir de um árduo trabalho nos seringais, favoreceram que a economia da borracha desenvolvesse de forma acelerada, e a grande presença dos brasileiros no Acre começou a inquietar a Bolívia que, por inúmeras vezes, tentou expulsá-los do território, sem sucesso.

Embora o governo brasileiro reconhecesse a região acreana como parte do território boliviano, muitos brasileiros insistiam em permanecer lá. Lutas foram travadas em diversas ocasiões entre os países vizinhos, segundo Calixto (1985, p. 119-129), na tentativa de incorporar o Acre ao território brasileiro, o Governo do Brasil acabou por convidar o gaúcho Plácido de Castro, para treinar seringueiros para práticas militares e liderar o movimento contra os inimigos bolivianos.

Apesar da inexperiência dos seringueiros, as tropas de Castro, após sucessivas batalhas, foram vitoriosas, derrotando o último foco de resistência boliviana em Puerto Alonso. Com a chegada dos primeiros exploradores, a região foi, aos poucos sendo demarcada, formando os seringais e as colocações às margens das principais bacias hidrográficas acreanas - Rio Juruá e Rio Purús - de extrema importância sócioeconômica para a locomoção, para a comunicação, para a alimentação, enfim, para a própria existência dessas novas populações (Cf. Tocantins, 1984, p. 32).

O processo migratório para a região acreana tem maior impulso entre $1877 \mathrm{e}$ 1879, quando houve a maior crise sócio-econômica na Região Nordeste (sobretudo no Ceará), decorrente da forte seca que assolou a região. Essa crise, somada ao incentivo e financiamento pelo Estado do Amazonas, favoreceu a migração desses povos para a região.

Lima (s/d, p. 24) registra que

[...] a primeira expedição a chegar em terras acreanas, foi a do cearense de Uruburetama, João Gabriel, com sua gente, no navio vapor Anajás, aportando nas barrancas do Acre (Aquiri), fundando os primeiros seringais e formando os primeiros núcleos populacionais.

Pode-se dizer que, particularmente para o povo acreano, seringueira, seringal, seringueiro e seringalista configuram elementos imprescindíveis no perfil sóciohistórico-cultural de seu lugar e de sua gente: traduzem o principal motivador 
(seringueira) da formação espacial (seringal) e dos elementos humanos (seringueiro e seringalista) que favoreceram o surgimento do Estado do Acre que conhecemos atualmente. Assim, torna-se evidente que sem a atuação dos seringueiros, possivelmente, o Acre não pertenceria ao Brasil. No entanto, como lembra Sousa (2007, p. 45), apoiado em Tocantins (1979) e Calixto et al. (1985), a formação humana da referida área não se deu tão somente com a entrada dos desbravadores nordestinos. Pelo menos dois outros momentos devem ser destacados: um momento anterior: a existência no território de sociedades indígenas; e um posterior: a chagada de grupos familiares provenientes do Sul e do Sudeste do Brasil.

[...] a região onde hoje está situado o Estado do Acre já estava ocupada muito antes da chegada de colonizadores, por índios pertencentes a grupos diversos. Antes da "descoberta" da borracha havia 50 grupos indígenas. Hoje, calcula-se a presença de apenas doze etnias (SOUSA, 2007, p. 45).

As nações indígenas existentes no Acre podem ser distribuídas em dois troncos lingüísticos: a) Pano (Nações: Kaxinawá, Yawanawá, Poyanawá, Jaminawá, Nukini, Arara, Shanenawá, Kutukina, Nawas); e, b) Aruak (Nações: Kulina, Ashaninka, Manchinery) (Cf. SOUZA, 2005, p. 25-26). Os índios pertencentes aos referidos troncos têm procedência peruana e chegaram ao Acre motivados pela intensa perseguição espanhola. Chegando à região, os índios do Tronco Pano passaram a dominar a região do Rio Juruá, e os do Tronco Aruak, a região do Rio Purus. O elemento indígena - ou caboclo amazônico, como prefere chamar Lima (s/d, p. 62-63) - constitui o primeiro ramo étnico formador do homem acreano.

O nordestino, por sua vez, constitui o segundo ramo étnico. Como já foi dito anteriormente, esse grupo humano abrigava-se em terras acreanas em busca de uma vida de farturas, riquezas. Outras vezes, buscava na floresta um alívio para o sofrimento favorecido pela intensa seca que castigava impiedosamente sua região de origem. $\mathrm{O}$ povoamento da região acreana, desde a primeira fase migratória, resultou, inicialmente, do encontro do elemento indígena com o elemento nacional nordestino.

Os nativos transmitiram aos imigrantes conhecimentos e habilidades imprescindíveis para a sobrevivência e o trabalho no meio florestal - que era absolutamente adversa à da sua terra de origem.

O seringueiro, isto é, o grupo social representante da Amazônia, trouxe um conjunto de traços culturais dos lugares de onde emigrou e, em contato com o novo 
ambiente, sofreu um processo de aculturação, surgindo assim novos valores na indústria extrativa da borracha (COÊLHO, 1982, p. 45).

A influência do nativo sobre o conquistador, segundo Rancy (1992, p. 51-53) está refletida: a) na alimentação: aproveitamento dos recursos naturais; b) na habitação: adequada utilização dos produtos florestais na confecção das barracas; c) nos meios de locomoção: abertura de caminhos na selva, ou mesmo na fabricação e utilização de pequenas embarcações; entre outros.

Enfim, para garantir sua sobrevivência naquele ambiente, o rude seringueiro assimilou muitos hábitos e valores dos nativos, além dos já citados, acrescente-se

a) o vocabulário utilizado para a identificação de espécies animais e vegetais, ou para os elementos geográficos que integram o ambiente onde viviam;

b) as crenças e lendas existentes na região que, de algum modo, passaram a orientar a vida e o trabalho dos desbravadores da selva.

Já o terceiro ramo étnico, segundo Lima (s/d, p. 64-65), teve uma participação menor nesse processo de miscigenação. "Eram sírios, libaneses, turcos, judeus e outros comerciantes de tradição. Eles vinham para o Acre em busca do enriquecimento, através da comercialização da borracha e da castanha”.

As marcas do branco eurasiano, contudo, podem ser percebidas em certas características físicas do homem genuinamente acreano, bem como no processo civilizatório dessa população nortista. Boa parte desses estrangeiros integrava o sistema de exportação da borracha, outros atuavam como seringalistas, seringueiros, marreteiros - chegando, até, a possuir navios e grandes casas comerciais na região.

Há que se acrescentar, ainda, um quarto ramo étnico que participou da formação humana do Acre: os paulistas - denominação genérica atribuída, pela população, aos imigrantes provenientes da região centro-sul do Brasil, na década de 1970, que aportaram na região acreana com o propósito de estabelecer fazendas e desenvolver atividades pecuárias.

Esses quatro grupos étnicos justificam o caráter multicultural da população acreana, misto de tradições indígenas locais com as tradições dos migrantes nordestinos que povoaram a região, a partir do início do século $\mathrm{XX}$, dos estrangeiros e dos migrantes de outras regiões do Brasil.

A presença de tribos indígenas, de outras nacionalidades e de brasileiros de várias regiões, se manifesta nas crenças e valores, 
nos hábitos e costumes, nas variações do falar acreano e o jeito de sentir e agir da gente da cidade (BEZERRA, 1993, p. 26).

Ao se acreanizarem, esses grupos foram, pouco a pouco, perdendo uma parcela de sua identidade cultural original, mas, ao mesmo tempo, absorvendo costumes, comportamentos e crenças da cultura nativa, exigidos pelas próprias condições ambientais e sociais.

\section{Aspectos metodológicos da pesquisa}

Os dados apresentados e analisados neste trabalho, selecionados do corpus do Projeto Atlas Toponímico da Amazônia Ocidental Brasileira, uma das pesquisas em operacionalização no CEDAC/UFAC (Centro de Estudos Dialetológicos da Universidade Federal do Acre), tem como fontes principais:

a) folhas cartográficas do Estado do Acre (2006) e da Amazônia Legal, disponibilizadas pelo IBGE/AC;

b) mapas cartográficos (1990): Microrregião do Alto Juruá (escala 1:2000 000), Cruzeiro do Sul (escala 1:660 000), Feijó (escala 1:750 000), Mâncio Lima (escala 1:400 000), Tarauacá (escala 1:800 000), Microrregião Alto Purus (escala 1:2000 000), Assis Brasil (escala 1:330 000), Brasiléia (escala 1:330 000), Manuel Urbano (escala 1:750 000), Plácido de Castro (escala 1:300 000), Rio Branco (escala 1:600 000), Senador Guiomard (escala 1:300 000), Sena Madureira (escala 1:800 000), Xapuri (escala 1:500 000); fornecidos pela Fundação de Tecnologia do Estado do Acre (FUNTAC);

c) dados do Programa Estadual de Zoneamento Ecológico-Econômico do Estado do Acre (2000), fornecidos pela Secretaria de Estado de Ciência, Tecnologia e Meio Ambiente (SECTMA);

d) inquéritos (corpus) do Centro de Estudos Dialectológicos do Acre (CEDAC), da Universidade Federal do Acre.

Para a catalogação e a análise dos dados seguem-se as orientações de Dick (1992, 1996), que leva em consideração dois critérios analíticos: o taxionômico (que envolve as 27 classificações taxionômicas), e o aspecto lingüístico (que envolve o campo etno dialetológico e o histórico cultural).

As categorias taxionômicas são distribuídas em dois grandes grupos: a) Taxes de Natureza Física e b) Taxes de Natureza Antropo-Cultural.

Caderno Seminal Digital Ano 16, no 13, V. 13 (Jan.- Jun/2010) - ISSN 1806 -9142 


\subsection{Taxionomias de natureza fisica: definições e exemplificações}

a) Astrotopônimos: topônimos relativos aos corpos celestes em geral. Ex. Estrela (RS);

b) Cardinotopônimos: topônimos relativos às posições geográficas em geral. Ex. Nortelândia (MT);

c) Cromotopônimos: topônimos relativos à escala cromática. Ex. Branquinha (AL);

d) Dimensiotopônimos: topônimos relativos às dimensões dos acidentes geográficos. Serra Alta (SC);

e) Fitotopônimos: topônimos relativos aos vegetais. Ex. Flores (PE);

f) Geomorfotopônimos: topônimos relativos às formas topográficas. Ex. Morros (MA);

g) Hidrotopônimos: topônimos relativos a acidentes hidrográficos em geral. Ex. Cachoeirinha (RS);

h) Litotopônimos: topônimos relativos aos minerais ao à constituição do solo. Ex. Areia (PB);

i) Meteorotopônimos: topônimos relativos a fenômenos atmosféricos. Ex. Chuvisca (RS);

j) Morfotopônimos: topônimos relativos às formas geométricas. Ex. Volta Redonda (RJ);

1) Zootopônimos: topônimos referentes aos animais. Ex. Cascavel (CE)

\subsection{Taxionomias de natureza antropo-cultural: definições e exemplificações}

a) Animotopônimos (ou Nootopônimos): topônimos relativos à vida psíquica, à cultura espiritual. Ex. Vitória (ES);

b) Antropotopônimos: topônimos relativos aos nomes próprios individuais. Ex. Barbosa (SP);

c) Axiotopônimos: topônimos relativos aos títulos e dignidades que acompanham nomes próprios individuais. Ex. Coronel Ezequiel (RN);

d) Corotopônimos: topônimos relativos a nomes de cidades, países, estados, regiões e continentes. Ex. Seringal Quixadá (AC); 
e) Cronotopônimos: topônimos relativos aos indicadores cronológicos representados pelos adjetivos novo(a), velho(a). Ex. Nova Aurora (GO);

f) Ecotopônimos: topônimos relativos às habitações em geral. Ex. Chalé (MG);

g) Ergotopônimos: topônimos relativos aos elementos da cultura material. Ex. Jangada (MT);

h) Etnotopônimos: topônimos relativos aos elementos étnicos isolados ou não (povos, tribos, castas). Ex. Capixaba (AC);

i) Dirrematopônimos: topônimos constituídos de frases ou enunciados lingüísticos. Ex. Passa e Fica (RN);

j) Hierotopônimos: topônimos relativos a nomes sagrados de crenças diversas, a efemérides religiosas, às associações religiosas e aos locais de culto. Ex. Capela (AL). Essa categoria subdivide-se em:

i. Hagiotopônimos: nomes de santos ou santas do hagiológio católico romano. Ex. Santa Luzia (BA)

ii. Mitotopônimos: entidades mitológicas. Ex. Exu (PE);

1) Historiotopônimos: topônimos relativos aos movimentos de cunho histórico, a seus membros e às datas comemorativas. Ex. Plácido de Castro (AC);

m) Hodotopônimos: topônimos relativos às vias de comunicação urbana ou rural. Ex. Ponte Alta (SC);

n) Numerotopônimos: topônimos relativos aos adjetivos numerais. Ex. Dois vizinhos (PR);

o) Poliotopônimos: topônimos relativos pelos vocábulos vila, aldeia, cidade, povoação, arraial. Ex. Vila Nova do Mamoré (RO);

p) Sociotopônimos: topônimos relativos às atividades profissionais, aos locais de trabalho e aos pontos de encontro da comunidade, aglomerados humanos. Ex. Pracinha $(\mathrm{SP})$;

q) Somatopônimos: topônimos relativos metaforicamente às partes do corpo humano ou animal. Ex. Braço do Trombudo (SC).

Vale ressaltar que esse mesmo modelo de análise é utilizado no Projeto ATB (Atlas Toponímico do Brasil) e em suas variantes regionais: Projeto ATESP (Atlas Toponímico do Estado de São Paulo), Projeto ATEMG (Atlas Toponímico do Estado de Minas Gerais), Projeto ATEMT (Atlas Toponímico do Estado de Mato Grosso) entre outros. 


\section{Análise dos dados}

Como o objetivo deste trabalho é mostrar reflexos da cultura nordestina na toponímia acreana, deter-nos-emos aos topônimos incluídos nas taxionomias de Natureza Antropo-Cultural.

Destacamos as seguintes taxes: Corotopônimos e Hierotopônimos.

\subsection{Os Corotopônimos}

Os topônimos selecionados do corpus e incluídos entre os corotopônimos deixam transparecer dois aspectos possíveis: o primeiro está relacionado à motivação sofrida pelo denominador (o seringueiro) no ato do batismo.

Neste caso, transparece o sentimento de saudade da terra de origem (no caso dos topônimos destacados, as cidades localizadas no nordeste brasileiro) e, que, a partir dessa "homenagem" ele consegue manter um vínculo com sua terra natal.

O segundo aspecto diz respeito ao do processo de miscigenação étnica, que constitui a gênese da formação populacional acreana.

Embora os topônimos apresentados a seguir sejam apenas os que fazem referência a cidades nordestinas, é válido esclarecer que outros topônimos foram encontrados no corpus referindo-se a cidades de outras regiões e até de outros países, como: Seringal Mato Grosso, Seringal São Paulo, Seringal Bolívia, Seringal Venezuela.

São esses os topônimos que fazem referência a cidades nordestinas:

\begin{tabular}{|l|l|}
\hline & Fortaleza \\
\hline Altamira & Lavras \\
\hline Moradenção Nova & Pernambuco \\
\hline Apudi & Quixadá \\
\hline Cajazeira & Viçosa \\
\hline & \\
\hline Canindé & \\
\hline
\end{tabular}




\subsection{Os Hierotopônimos}

Nesses topônimos há reflexos, talvez, de uma das maiores características culturais nordestinas: o misticismo religioso.

Dadas as condições de vida dos seringueiros acreanos, solitários, na maioria das vezes, num meio florestal, sujeito aos perigos advindos da própria natureza ou as doenças típicas desses meios, como a malária; é justificável o sentimento de fé e crença religiosa nos seringueiros e em seus familiares.

Eis os topônimos desse grupo

\begin{tabular}{|c|l|}
\hline Santa Ana & Santa Cruz \\
\hline São José & SantaFé \\
\hline São Filismino & Santa Júlia \\
\hline Santa Maria & São Bento \\
\hline Santa Quitéria & São João da Barra \\
\hline Santo Antônio & São Domingos \\
\hline & \\
\hline São João & São Pedro \\
\hline São Raimundo & \\
\hline
\end{tabular}

Vale apresentar alguns topônimos incluídos na categoria taxionômica Dirrematopônimos, mas que marcam a religiosidade dos seringueiros:

Colocação Deus é bom

Colocação Livre-nos-Deus

\section{Considerações finais}

O perfil cultural da sociedade acreana, num sentido amplo e generalizante, constitui uma mescla de valores, atitudes, costumes, crenças, conhecimentos etc., que foi sendo construído (e ainda está) desde os primeiros contatos dos imigrantes com os índios que já ocupavam a região. 
E, em seguida, com o branco eurasiano, e com os "paulistas". A cultura acreana, em síntese, foi formada através das trocas de saberes, de práticas e de comportamentos entre esses referidos grupos humanos, especialmente.

$\mathrm{Na}$ análise dos topônimos de natureza antropo-cultural: corotopônimos e hierotopônimos foi perceptível, a priori, a valorização dos aspectos sócio-culturais no ato de nomear as colocações e os seringais acreanos.

O valor atribuído aos referidos aspectos pode ser justificado pela própria história do grupo humano que formou o referido lugar (e que não difere da dos outros seringais acreanos): famílias que migraram para o local fugindo da seca (no caso dos nordestinos), na esperança de uma vida melhor, para si próprios e para os filhos, deparando-se com uma realidade físico-geográfica absolutamente diversa daquela de onde migraram, e não só isso, decepcionados com a realidade econômico social a que estavam sujeitos, chegando quase à escravidão.

Para os seringueiros, portanto, os espaços onde, agora, moravam eram uma espécie de prolongamento da região de onde tinham saído. Esse resultado confirma a tese sapiriana (1969) de que o ambiente (seja físico, seja social) reflete-se na língua.

No caso do estudo aqui apresentado, o enunciador do topônimo, no ato do batismo dos acidentes analisados, condicionado por fatores físico-ambientais, transformou uma unidade da língua em um nome próprio, ou seja, de unidade virtual o signo adquiriu a estatuto de fato lingüístico, condicionado for fatores extralingüísticos.

\section{Referências bibliográficas}

ARAÚJO, M. G. J. de. Entre almas, encantos e cipó. Campinas, SP: 1998. Dissertação (Mestrado) - Unicamp.

BEZERRA, M. J. (org). Cidade de Rio Branco - a marca de um tempo: história, povo e cultura. Rio Branco: Globo, 1993.

CALIXTO, V. de O. et al. Acre uma história em construção. Rio Branco: Fundação de Desenvolvimento de Recursos Humanos, da Cultura e do Desporto/ Secretaria de Educação, 1985.

COËLHO, E. M. Acre: o ciclo da borracha (1903 - 1975). Niterói: 1982. Dissertação (Mestrado) - UFF, 1982.

DICK, M. V. de P. do A. O problema das taxeonomias toponímicas. Uma contribuição metodológica. Separata de Língua e Literatura. n. IV, p. 373-380, 1975. Estado, 1990.

A motivação toponímica e a realidade brasileira. São Paulo: Arquivo do 
. Toponímia e Antroponímia no Brasil. Coletânea de estudos. São Paulo: Gráfica da FFLCH/USP, 1992.

Atlas toponímico: um estudo de caso. Actas del XI Congreso Internacional de la Asociación de Linguística y Filologia de la América Latina. Universidad de Las Palmas de Gran Canaria, 1996.

Atlas toponímico: um estudo dialetológico. Revista Philologus. Rio de janeiro, v. 10, 1998. DOSSE, F. História do estruturalismo. O campo do signo. Rio de Janeiro: Editora Ensaio, 1993.

GUIRAUD, P. A semântica. São Paulo: DIFEL, 1973.

ISQUERDO, A. N. O fato lingüístico como recorte da realidade sócio-cultural. São Paulo: 1996. Tese (Doutorado) - Universidade Estadual Paulista.

MARTINELLO, P. A. A “batalha da borracha” na segunda guerra mundial e suas conseqüências para o vale amazônico. Cadernos da UFAC. Rio Branco: EDUFAC, 1988.

MOULY, G. J. Psicologia educacional. São Paulo: Pioneira, 1970.

RANCY, C. M. D. Raízes do Acre (1870 - 1912). Rio Branco: M. M. Paim, 1992.

SALAZAR-QUIJADA, A. La toponímia em Venezuela. Caracas: Universidad Central de Venezuela, 1985.

SOUSA, A. M. de. Desbravando a Amazônia Ocidental Brasileira: estudo toponímico de acidentes humanos e físicos acreanos. Fortaleza, 2007. Tese (Doutorado) - Universidade Federal do Ceará.

TOCANTINS, L. Formação histórica do Acre. Rio de Janeiro: Civilização Brasileira, 1979.

ULLMANN, S. Semântica: uma introdução à ciência do significado. Lisboa: Fundação Calouste Gulbenkian, 1964.

Caderno Seminal Digital Ano 16, nº 13, V. 13 (Jan.- Jun/2010) - ISSN 1806 -9142 